\title{
Aberrant ABO B Phenotype with Irregular Anti-B Caused by a Para-Bombay FUT1 Mutation
}

\author{
Eva Maria Matzhold ${ }^{\mathrm{a}}$ Thomas Wagner ${ }^{\mathrm{a}}$ Camilla Drexler $^{\mathrm{a}}$ \\ Marlies Schönbacher ${ }^{b}$ Günther F. Körmöczi ${ }^{\text {b }}$ \\ ${ }^{a}$ Department of Blood Group Serology and Transfusion Medicine, Medical University of Graz, Graz, Austria; \\ ${ }^{b}$ Department of Blood Group Serology and Transfusion Medicine, Medical University of Vienna, Vienna, Austria
}

\section{Keywords}

ABO blood group $\cdot$ FUT1 $\cdot$ H-deficient secretor $\cdot$ Irregular anti-B · Para-Bombay

\begin{abstract}
Background: Routine $\mathrm{ABO}$ blood group typing for pre-transfusion testing of a male Austrian patient of Far Eastern origin showed discrepant results with an apparently weak blood group $\mathrm{B}$ phenotype and irregular anti-B. Materials and Methods: $\mathrm{ABH}$ phenotyping and cross-matching was done by standard serologic techniques and levels of $\mathrm{H}$ expression were determined by flow cytometry. $A B O$ gene sequencing including regulatory regions as well as analysis of FUT1 $(\mathrm{H})$, FUT2 (Secretor), and FUT3 (Lewis) were carried out. Results: While monoclonal $\mathrm{ABO}$ antigen typing indicated blood group $O$, weak agglutination reactions using polyclonal human anti-B and anti-AB were seen. In reverse typing at room temperature, the plasma was reactive with $A 1$ and $A 2$ RBCs and negative with $B$ and $O$ cells, whereas at $4{ }^{\circ} \mathrm{C}$, anti- $B$ reactivity was found. The indirect anti-globulin cross-match of the patient's plasma was positive with group B RBCs and negative with group O RBCs. Sequencing analysis showed the presence of $A B O^{*} B .01$ (B114) allele and homozygosity for the FUT1 mutation c.551_552delAG. Flow cytometry demonstrated trace amounts of $\mathrm{H}$ antigen on the patient's RBCs.
\end{abstract}

Conclusion: While a functional $B$ allele was found, analysis of FUT1 and FUT2 genes revealed the presence of a rare paraBombay genotype $\mathrm{O}_{h}{ }^{\mathrm{B}}$. Interestingly, no anti-H but irregular anti-B was found in the patient's plasma, responsible for the positive cross-match with group B RBCs. Even though very rare and not reported for the European population, the presence of an H-deficient phenotype should be considered when investigating individuals with an unusual $A B O$ blood group type.

(c) 2019 S. Karger AG, Basel

\section{Introduction}

Blood group A and B antigen synthesis is dependent on the presence of precursor $\mathrm{H}$ carbohydrate structures. $\mathrm{H}$ antigen expression on red blood cells (RBCs) is regulated by the fucosyltransferase 1, product of the FUT1 gene, while fucosyltransferase 2, encoded by the FUT2 gene, regulates the expression of soluble $\mathrm{ABH}$ antigens in secretions. Mutations in the FUT1 gene may result in reduced or absent $\mathrm{H}$ antigen production on RBCs, while nonfunctional FUT2 alleles when homozygous result in the non-secretor phenotype. Inactivity of both, fucosyltransferase 1 and 2, characterizes the Bombay phenotype $\left(\mathrm{O}_{\mathrm{h}}\right)$. In the para-Bombay phenotypes, $\mathrm{ABH}$ antigens are 
A

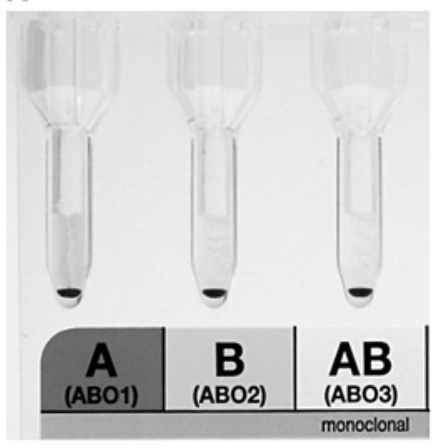

Fig. 1. $A B O$ forward and reverse typing. $\mathrm{ABO}$ antigen typing using monoclonal reagents (A) showed generally negative results, as opposed to positive reactions with polyclonal reagents (B) enhanced by bromelin pretreatment of red cells (slightly positive and +++ with anti-B and anti- $\mathrm{AB}$, respectively). $\mathrm{ABO}$ reverse typing of the patient's plasma in neutral gel showed reactivity with A1 and A2 cells at room temperature (RT; C), and additionally with $B$ cells at $4{ }^{\circ} \mathrm{C}$ (D).
C

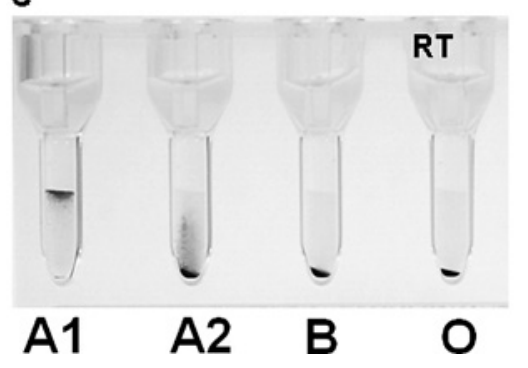

B

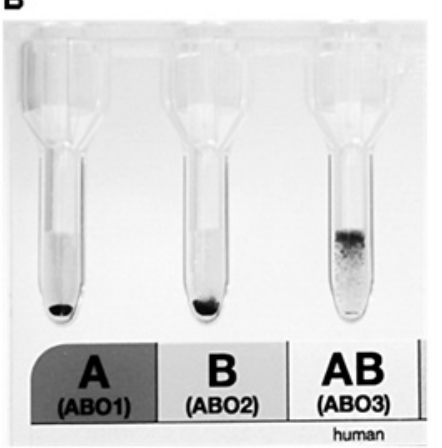

D

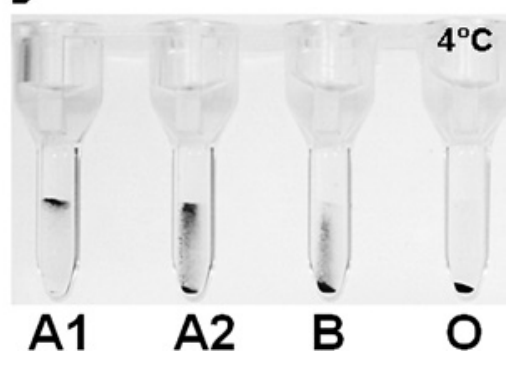

deficient in secretors or partially deficient in both secretors and non-secretors $[1,2]$.

Genetic polymorphisms of FUT1 and FUT2 are ethnically and geographically specific. Alleles of FUT1 are rare and occur sporadically, whereas the FUT2 gene is highly polymorphic and is distributed in a population-specific manner [3-7]. Variants of fucosyltransferases 1 and 2 may be the reason for discrepant serologic $A B O$ blood group typing results. Here we report an aberrant $B$ phenotype with irregular anti- $\mathrm{B}$ caused by a disruptive mutation in FUT1 of a male Austrian patient of Far Eastern origin.

\section{Materials and Methods}

Serologic ABO and Lewis blood typing was performed using gel matrix techniques (MicroTyping system, Bio-Rad, Vienna, Austria). The presence of $\mathrm{H}$ antigen was tested using two monoclonal anti-H (MIMA134, provided by G. Halverson, New York Blood Center, New York, NY; 10934C11, BAG, Lich, Germany) in gel matrix (Bio-Rad). Additionally, $\mathrm{H}$ antigen expression was analyzed by flow cytometry using fluorescein isothiocyanate-conjugated anti-H (BRIC198, International Blood Group Reference Laboratory, Bristol, UK; FACSCanto II, Becton Dickinson, Heidelberg, Germany). Polyclonal anti-A or anti-B (Biotest, Dreieich, Germany) was adsorbed onto the patient's RBCs, followed by acid elution (DiaCidel, DiaMed). Eluates were tested against A1, A2, B, and O RBCs. Cross-matching of the patient's plasma with group $\mathrm{O}$ and $\mathrm{B}$ RBCs was performed in anti-human globulin and neutral gel cards (Bio-Rad) at $37^{\circ} \mathrm{C}$ and room temperature, respectively. Anti-erythrocyte antibody screening and the direct anti-human globulin test (DAT) was done as described [8]. Allele-specific sequencing analyses of the $\mathrm{ABO}$ gene and its regulatory regions, as well as of FUT1, FUT2, and FUT3 genes were performed as previously described $[6,9]$.

\section{Results}

Testing the patient's RBCs with monoclonal ABO typing reagents indicated blood group $\mathrm{O}$. In contrast, when using polyclonal reagents after RBC pretreatment with bromelin, weak agglutination reactions were seen with anti-B and anti-AB $(-/+$ and +++ , respectively; Fig. $1 \mathrm{~A}$ and $\mathrm{B}$ ). In reverse blood group typing at room temperature, the serum was strongly reactive with $\mathrm{A} 1 \mathrm{RBCs},++$ reactive with $\mathrm{A} 2$, and negative with $\mathrm{B}$ and $\mathrm{O}$ cells. However, reverse typing at $4{ }^{\circ} \mathrm{C}$ showed the presence of anti-B $(++)$ (Fig. 1C and D). The patient's plasma showed a negative antibody screening, and his RBCs were negative in the DAT.

Adsorption-elution studies with the patient's RBCs revealed negative results with anti- $A$, but positive reactions with anti-B, confirming a weak B phenotype. Crossmatch of the patient's plasma was positive with two of three group B RBC samples in both, the anti-humanglobulin phase at $37^{\circ} \mathrm{C}$ and saline phase at room temperature. Cross-match was generally negative with group $\mathrm{O}$ RBCs (data not shown). $\mathrm{H}$ antigen was not detected in RBC hemagglutination typing (Fig. 2A). Flow cytometry 


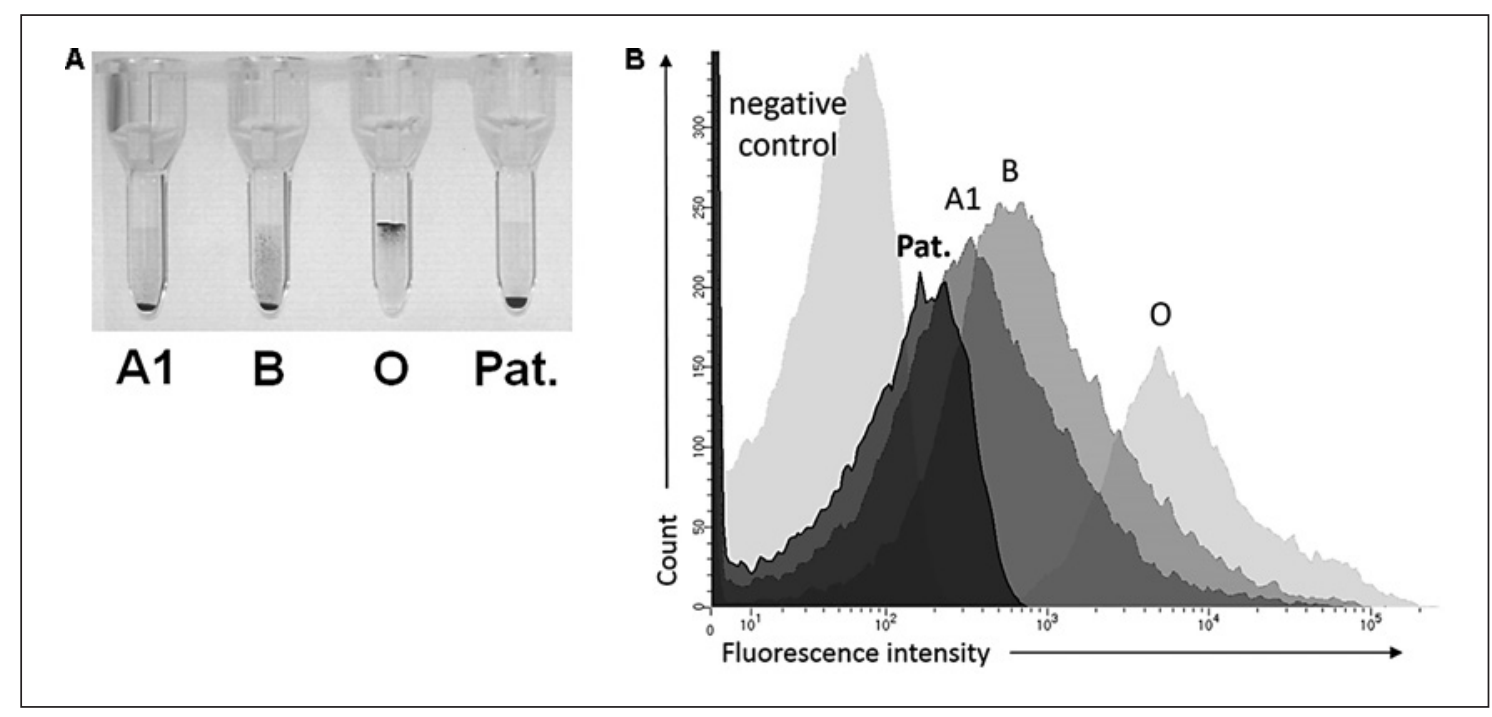

Fig. 2. $H$ antigen expression. Serologic $H$ antigen typing of the patient's RBCs (Pat.) using monoclonal anti-H (HIMA134) in neutral gel cards was negative (A). Identical results were obtained with another anti-H (10934C11; not shown). Flow cytometric analysis using fluorochrome-conjugated anti-H (BRIC198) detected minimal amounts of $\mathrm{H}$ antigens on the patient's RBCs (B). For comparison, A1, B, and O control RBCs are shown.

indicated trace amounts of $\mathrm{H}$ antigen on the patient's RBCs, even less than on A1 control cells (Fig. 2B).

By sequencing analysis, the alleles $A B O^{*} O .01 .01$ and a variant of $A B O^{*} B .01$ (B114) were identified. The FUT1 genotype showed homozygosity for $F U T 1^{*} 01 N .06$ allele, containing a nucleotide deletion of one of three AG repeats (c.551_552delAG, p.Glu184Valfs*85) in the coding region of the gene [10]. FUT2 was homozygous for the functional Se357 allele (c.357C >T, p.Asn119Asn119) [11], indicating secretor status. Consistent with the patient's Le(a-b-) phenotype, FUT3 sequencing detected homozygosity for inactive Lewis alleles based on the presence of c.59T $>$ G (p.Leu20Arg) and c.1067T $>$ A (p.I356K) $[12,13]$.

\section{Discussion}

The presence of a functional $B$ allele in the genotype does not reflect the aberrant $\mathrm{ABO}$ blood group phenotype of the investigated patient. However, the detected sequence variant in FUT1 gene encodes a mutation previously found in a few individuals in Taiwan. Since the deletion results in a reading frame shift creating a premature stop codon in the coding region, nonfunctional $\alpha(1,2) \mathrm{fu}$ cosyltransferase enzymes may be expressed [10]. Functional FUT2 alleles are present, indicating an $\mathrm{H}$-deficient secretor type $\mathrm{O}_{\mathrm{h}}{ }^{\mathrm{B}}$-secretor.

The minimal presence of $\mathrm{H}$ antigens on the patient's RBCs was only recognized applying flow cytometry analysis, known to be more sensitive than serological typing by direct agglutination. Due to the secretor status of the patient, soluble $\mathrm{H}$ antigen synthesized by FUT2, as well as the $\mathrm{B}$ antigens detected may be adsorbed on the RBCs described as $\mathrm{O}_{\mathrm{h}}{ }^{\mathrm{B}}$ phenotype $[14,15]$.

Like those with the Bombay phenotype, para-Bombay individuals may develop antibodies against the $\mathrm{H}$ antigens $[16,17]$. However, no anti-H was observed in the serum of our patient.

Interestingly, anti-B was found in the patient's plasma at $4{ }^{\circ} \mathrm{C}$, suggesting the presence of irregular anti- $\mathrm{B}$ being responsible for a positive crossmatch with group B RBCs.

No previous blood transfusion is known and unfortunately, family history data were not available.

When transfusion is indicated, group O RBCs appear to be compatible for this patient. Donor blood of the same phenotype is - aside from family donors - exceedingly rare in Europe and was no option in this case. In case of allo-anti $\mathrm{H}$ development, the transfusion strategy has to be revised.

The presence of anti- $\mathrm{H}$ in $\mathrm{H}$-deficient secretors was reported [16, 17]; however, as para-Bombay individuals usually retain some $\mathrm{H}$ antigens on their RBCs, only weak or no anti-H activity may be observed in their plasma.

The para-Bombay phenotype is slightly more common in Taiwan with a frequency of about 1 in 8,000 people [18], but not reported in the Austrian population. Since anti-H antiserum is not routinely applied for $A B O$ typing, cases of para-Bombay phenotype would remain unidentified. Even though very rare, especially when investigating individuals of Far Eastern origin showing an unusual $\mathrm{ABO}$ blood group type, the presence of a H-de- 
ficient phenotype should be considered. In such phenotypes, particular attention should be paid to potential aberrant reverse typing results to ensure transfusion safety.

\section{Acknowledgements}

The authors thank Anja Stoisser for her technical assistance.

\section{Statement of Ethics}

The patient has given informed consent. No ethical approval was required.

\section{Disclosure Statement}

The authors have no conflicts of interest to declare.

\section{Funding Sources}

The study did not receive any funding.

\section{Author Contributions}

Eva Maria Matzhold wrote the manuscript, which was conceptually designed by Günther F. Körmöczi and Thomas Wagner. Marlies Schönbacher, Eva Maria Matzhold, and Günther F. Körmöczi performed the laboratory tests and compiled the data. Camilla Drexler revised the work critically and prepared the figures. All authors approved the manuscript for submission.

\section{Web-Based Resources}

http://www.isbtweb.org/fileadmin/user_upload/Working_ parties/WP_on_Red_Cell_Immunogenetics_and/018_H_Alleles_v5.1_170221.pdf. The URL was accessed on April 5, 2018.

\section{References}

1 Larsen RD, Ernst LK, Nair RP, Lowe JB. Molecular cloning, sequence, and expression of a human GDP-L-fucose:beta-D-galactoside 2-alpha-L-fucosyltransferase cDNA that can form the $\mathrm{H}$ blood group antigen. Proc Natl Acad Sci USA. 1990 Sep;87(17):6674-8.

2 Kelly RJ, Rouquier S, Giorgi D, Lennon GG, Lowe JB. Sequence and expression of a candidate for the human Secretor blood group alpha $(1,2)$ fucosyltransferase gene (FUT2). Homozygosity for an enzyme-inactivating nonsense mutation commonly correlates with the non-secretor phenotype. J Biol Chem. 1995 Mar;270(9):4640-9.

3 Wagner FF, Flegel WA. Polymorphism of the $\mathrm{h}$ allele and the population frequency of sporadic nonfunctional alleles. Transfusion. 1997 Mar;37(3):284-90.

4 Koda Y, Soejima M, Kimura H. The polymorphisms of fucosyltransferases. Leg Med (Tokyo). 2001 Mar;3(1):2-14.

5 Pang H, Koda Y, Soejima M, Fujitani N, Ogaki T, Saito A, et al. Polymorphism of the human ABO-Secretor locus (FUT2) in four populations in Asia: indication of distinct Asian subpopulations. Ann Hum Genet. 2001 Sep; 65(Pt 5):429-37.

6 Matzhold EM, Helmberg W, Wagner T, Drexler C, Ulrich S, Winkler A, et al. Identification of 14 new alleles at the fucosyltransferase 1, 2, and 3 loci in Styrian blood donors, Austria. Transfusion. 2009 Oct;49(10):2097108.
7 Storry JR, Johannesson JS, Poole J, Strindberg J, Rodrigues MJ, Yahalom V, et al. Identification of six new alleles at the FUT1 and FUT2 loci in ethnically diverse individuals with Bombay and Para-Bombay phenotypes. Transfusion. 2006 Dec;46(12):2149-55.

8 Gassner C, Utz I, Schennach H, Ramoni A, Steiner H, Scholz S, et al. Novel RHD alleles with weak hemagglutination and genetic Exon 9 diversity: weak D Types 45.1, 75, and 76. Transfusion. 2013 Nov;53(11 Suppl 2): 2954-9.

9 Matzhold EM, Drexler C, Staudacher E, Glock B, Wagner T. A novel variant B allele at the $\mathrm{ABO}$ gene locus characterized by a duplication-based insertion of 27 nucleotides identified in an Iraqi male with a weak B subgroup phenotype. Transfusion. 2018 May; 58(5): 1318-9.

10 Yu LC, Yang YH, Broadberry RE, Chen YH, Lin M. Heterogeneity of the human $\mathrm{H}$ blood group alpha $(1,2)$ fucosyltransferase gene among para-Bombay individuals. Vox Sang. 1997;72(1):36-40.

11 Yu LC, Yang YH, Broadberry RE, Chen YH, Chan YS, Lin M. Correlation of a missense mutation in the human Secretor alpha 1,2-fucosyltransferase gene with the Lewis $(a+b+)$ phenotype: a potential molecular basis for the weak Secretor allele (Sew). Biochem J. 1995 Dec;312(Pt 2):329-32.

12 Mollicone R, Reguigne I, Kelly RJ, Fletcher A, Watt J, Chatfield S, et al. Molecular basis for
Lewis alpha(1,3/1,4)-fucosyltransferase gene deficiency (FUT3) found in Lewis-negative Indonesian pedigrees. J Biol Chem. 1994 Aug; 269(33):20987-94.

13 Koda Y, Kimura H, Mekada E. Analysis of Lewis fucosyltransferase genes from the human gastric mucosa of Lewis-positive and -negative individuals. Blood. 1993 Nov;82(9): 2915-9.

14 Dzierzkowa-Borodej W, Meinhard W, Nestorowicz S, Piróg J. Successful elution of anti-A and certain anti-H reagents from two "Bombay" (O A H ) blood samples and investigation of isoagglutinins in their sera. Arch Immunol Ther Exp (Warsz). 1972;20(6):841-9.

15 Rodier L, Lopez M, Liberge G, Badet J, Gerbal A, Salmon C. Anti-h absorbed by, and eluted from Oh (Bombay) red blood cells. Biomedicine. 1974 Jul;21(7):312-6.

16 Yan L, Zhu F, Xu X, Hong X, Lv Q. Molecular basis for para-Bombay phenotypes in Chinese persons, including a novel nonfunctional FUT1 allele. Transfusion. 2005 May;45(5):725-30.

17 Mak KH, Lubenko A, Greenwell P, Voak D, Yan KF, Poole J. Serologic characteristics of $\mathrm{H}$-deficient phenotypes among Chinese in Hong Kong. Transfusion. 1996 Nov-Dec; 36(11-12):994-9.

18 Chen DP, Tseng CP, Wang WT, Peng CT, Tsao KC, Wu TL, et al. Two prevalent $h$ alleles in para-Bombay haplotypes among 250,000 Taiwanese. Ann Clin Lab Sci. 2004;34(3): 314-8. 